Hammersmith Staff Rounds

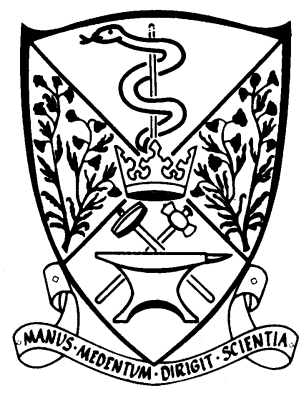

\title{
Campylobacter pylori, duodenal ulcer disease, and gastrin
}

\author{
Hypergastrinaemia due to bacterial colonisation responds to antibiotics
}

Campylobacter pylori is a gram negative spiral bacterium that produces a powerful urease that splits urea with the production of ammonia. By neutralising intragastric $\mathrm{pH}$ with ammonia $C$ pylori is able to colonise the stomach and survive conditions unsuitable for other bacteria. We present a patient who illustrates the relation between $C$ pylori and plasma gastrin concentration and whose duodenal ulcer disease was healed only after treatment was aimed at eradication of $C$ pylori.

\section{History}

The patient was a 32 year old stocktaker. He gave a two year history of recurrent abdominal pain in the epigastrium and right upper quadrant. The pain was sharp, usually occurring between meals, and woke him in the early hours of the morning. He smoked 20 cigarettes daily and drank 10 units of alcohol each week. He had not taken aspirin or other non-steroidal anti-inflammatory drugs. Physical examination yielded normal results.

In May 1988 he had been prescribed a course of ranitidine $150 \mathrm{mg}$ twice daily, and his symptoms were relieved within two days. Two months later, however, his symptoms recurred after stopping treatment, and endoscopy showed duodenal ulceration. Ranitidine was restarted and a repeat endoscopy after six weeks confirmed healing. He remained well taking a maintenance dose of ranitidine (150 mg nightly) until December 1988 when he suffered further symptoms.

Further endoscopy at this time confirmed the presence of duodenal ulcer disease. Multiple biopsy specimens were taken and showed $C$ pylori and mild chronic gastritis (fig 1). A test for urease was done by placing two antral biopsy specimens in a solution of urea and phenol red (fig 2). The presence of $C$ pylori was indicated by the change in colour from yellow to pink, signifying the hydrolysis of urea to ammonia by urease, with net production of alkali. Studies of acid secretion showed a high basal acid output of $10 \mathrm{mmol} / \mathrm{h}$ (normal $<5 \mathrm{mmol} / \mathrm{h}$ ) and a high pentagastrin-stimulated acid output of $46 \mathrm{mmol} / \mathrm{h}$ (normal $<35 \mathrm{mmol} / \mathrm{h}$ ). Basal plasma gastrin concentration was $20 \mathrm{pmol} / \mathrm{l}$, and peak meal stimulated gastrin concentration was $100 \mathrm{pmol} / \mathrm{l}$,

of medicine

Discussion group:

S R Bloom, FRCP, professor of endocrinology

J Calam, FRCP, senior lecturer in medicine (gastroenterology)

T M Cox, FRCP, senior lecturer in medicine (haematology)

H J F Hodgson, FRCP, reader in medicine (gastroenterology)

M S Losowsky, FRCP, visiting professor

M B Pepys, FRCP, professor of immunological medicine N A Wright, FRCPATH, professor of histopathology

$\mathrm{O} M$ Wrong, FRCP, visiting professor

Series edited by:

Dr Robert Winter.

BrMed f 1989;299: 1093-4
FIG 1-Biopsy specimen of gastric antral mucosa (stained with haematoxylin and eosin), showing mild chronic gastritis and numerous spiral bacteria in crypt

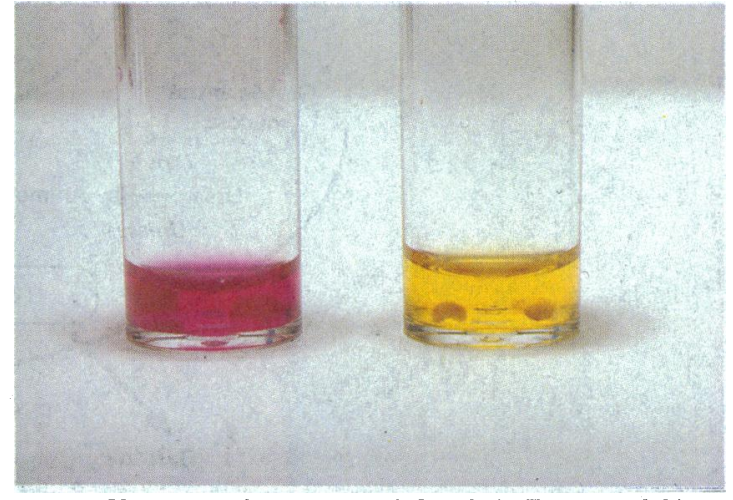

FIG 2-Urease test for presence of $C$ pylori. Two antral biopsy specimens are crushed in $0.5 \mathrm{ml}$ of solution of urea $(20 \mathrm{~g} / \mathrm{l})$, potassium dihydrogen orthophosphate $(2 \mathrm{~g} / \mathrm{l})$, and phenol red $(0.04 \mathrm{~g} / \mathrm{l})$ as indicator. Urease activity results in production of ammonia and colour change from yellow to pink

which was above the normal range $(<60 \mathrm{pmol} / \mathrm{l})$ and typical of concentrations seen in duodenal ulcer disease.

Treatment was started to eradicate $C$ pylori and consisted of metronidazole $400 \mathrm{mg}$ thrice daily for two weeks and colloidal bismuth subcitrate (DeNol) 120 $\mathrm{mg}$ four times daily for four weeks. His symptoms completely resolved within one week, and one month later his ulcer had healed. Histological examination and repeat urease testing confirmed eradication of antral $C$ pylori. His pentagastrin-stimulated acid output had also fallen to $25 \mathrm{mmol} / \mathrm{h}$, and his peak meal stimulated gastrin concentration was $60 \mathrm{pmol} / \mathrm{l}$. Six months later the patient was well without further treatment.

\section{Comment}

Patients with duodenal ulcer disease tend to have higher rates of acid secretion, whether stimulated by pentagastrin or by meals, as well as high plasma gastrin concentrations after meals. This is surprising because increased gastric acid should inhibit release of gastrin. Thus the hypergastrinaemia can be considered inappropriate, suggesting a failure of regulation of gastrin release from antral $\mathrm{G}$ cells. In support of this low intragastric $\mathrm{pH}$ has been shown to inhibit release of antral gastrin less effectively in patients with duodenal ulcer disease than in normal subjects. ${ }^{2}$ We wondered whether the powerful urease produced by $C$ pylori may (through the local production of ammonia) increase the $\mathrm{pH}$ within the mucus layer that overlies the gastric antrum. The normal inhibition of gastrin by increased intraluminal acid would be impaired because the cells would see only the (falsely high) local pH. The persistently and inappropriately raised gastrin would not only increase the amount of acid secreted but also in time increase the acid-secreting fundic parietal cell mass.

We examined this hypothesis in a group of patients similar to the patient presented, all with active duodenal ulcer disease at endoscopy. In this study 25 of the 31 patients were positive for $C$ pylori by the urease test performed on antral biopsy specimens. Peak pentagastrin-stimulated acid secretion was significantly 
higher in the patients positive for $C$ pylori than in those negative for it with duodenal ulcer disease. Furthermore, plasma gastrin concentrations after meals were more than twice those in the patients positive for $C$ pylori than in those negative for it. ${ }^{3}$ Thus in $C$ pylori infection of the gastric antrum there is increased gastrin production. This increase is probably due to the local production of ammonia and resultant local changes in $\mathrm{pH}$ (fig 3).

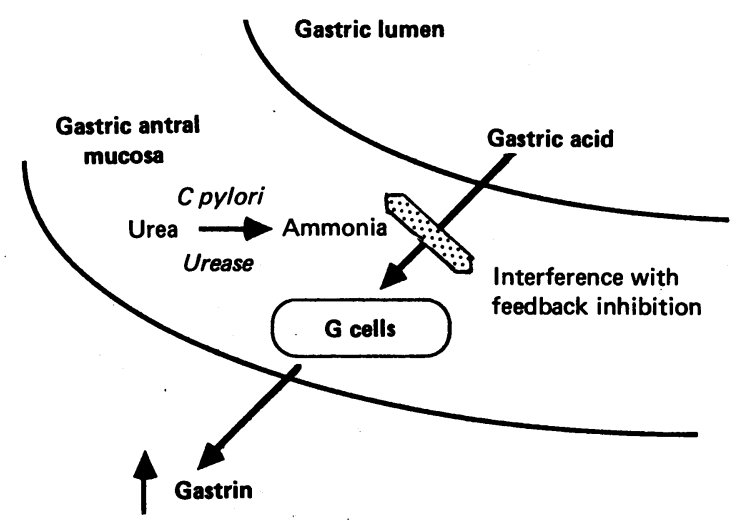

FIG 3-Disturbance of normal feedback inhibition of acid on gastrin release. Urease activity as a result of $C$ pylori produces alkaline microenvironment in antral mucosa, thereby interfering with normal feedback inhibition of acid on gastrin release

\section{Discussion}

JC: This brings together several strands of evidence in relation to the aetiology of duodenal ulcer disease. The disease is believed to be the common end result of several different physiological abnormalities contributing to ulceration. This patient led us to question whether acid secretion and the role of $C$ pylori were independent risk factors for the disease or if there was a relation between them. If they were independent we would have expected to see similar acid secretion in patients positive and negative for urease (or perhaps even more acid in the patients negative for urease to cause ulceration in the absence of the organism). In fact we found increased acid secretion in patients infected with $C$ pylori, and this does fit in with the hypothesis presented.

CTD: Are you sure that the characteristics of the patients negative for $C$ pylori in your study were not radically different from those positive for it?

SL: The two groups were similar with respect to age, sex, and duration of disease.

SRB: There has been a considerable amount of work over the years showing clearly that patients with duodenal ulcer disease have a higher acid-gastrin product - that is, they have either higher acid output or higher gastrin, or both. Until now this has fitted uneasily with the observation that a high proportion of patients are infected with $C$ pylori, an organism that can reduce gastric acid. This new hypothesis would seem to overcome the apparent paradox nicely. Further proof will come from the study of the response to treating infection with $C$ pylori in series of patients.

MSL: These organisms were described at the turn of the century and again more recently, but people have dismissed them because no one could believe that duodenal ulcer disease may be an infectious disease. A further point I would add in support of this hypothesis is that $C$ pylori is capable of producing high concentrations of urease.

NAW: $C$ pylori does not usually colonise the duodenal mucosa except when there is pyloric metaplasia, as seen in patients with duodenitis or duodenal ulcers.
Do your patients with antral $C$ pylori colonisation also show colonisation of these metaplastic areas in the duodenum, and if so do you think that a direct local toxic effect on the duodenum is possible through this mechanism?

JC: We have started to look at this, but this patient did not have a duodenal biopsy. I do not think our results refute the possibility that the position of the ulcer in the duodenum is in some way related to gastric metaplasia.

TMC: Marshall, who rekindled interest in $C$ pylori inoculated himself with the organism and showed that it could be passaged in that way. I wonder whether Koch's postulates may be applied here. ${ }^{4}$ Would it, for example, be possible to test definitively whether the organism induced the acid abnormalities and if so what was the time course from inoculation?

MSL: Of the two cases described in reports permanent self induced infection with $C$ pylori has occurred in both. Various animal models exist, but their applicability to humans with duodenal ulcer disease is questionable.

OMW: Much has been written about gastric urease. I think that the general view is that some of it is not bacterial. I wonder how the $C$ pylori story fits in with what is known about gastric urease.

JC: $M y$ understanding is that all gastric urease is attributable to $C$ pylori.

MBP: It should be fairly straightforward to resolve the urease question immunohistochemically. There must be antigenic differences between $C$ pylori urease and human urease in the stomach. This may also lead to a more sophisticated diagnostic quick test for the presence of $C$ pylori in the biopsy specimen.

HJFH: To pursue the question of infection. We have talked about $C$ pylori in the context of duodenal ulcer disease; the other role of $C$ pylori is in the development of acute and chronic gastritis, and this is where most studies have been done in volunteers. This produces a different disease, so it is not going to be possible to fulfil Koch's postulate for duodenal ulcer disease in this way. The patient and data presented raise intriguing questions about, for example, familial hypergastrinaemia and familial duodenal ulcers and to what extent these are going to be based on the absence or presence of genetically determined adherence factors that make infection and long term colonisation with these organisms more likely.

CTD: Viewed from the point of good clinical management of this common condition when should $C$ pylori be looked for and when is treatment with antibiotics indicated?

JC: The history of repeated relapses of duodenal ulcers after withdrawal of treatment with histamine-2 receptor antagonist should certainly prompt investigation for $C$ pylori and, if $C$ pylori is present, treatment with antibiotics. The test for urease on gastric biopsy specimens is fairly easy to perform and entails crushing two antral biopsy specimens in a solution of urea containing phenol red. A change in colour from yellow to pink indicates the presence of $C$ pylori. Testing for acid secretion is a simple procedure performed on an outpatient basis and is measured by continuous gastric aspiration followed by a test meal during which blood is taken for gastrin radioimmunoassay.

1 Dooley CP, Cohen $\mathrm{H}$. The clinical significance of Campylobacter pylori. Ann Intern Med 1988;108:70-9.

2 Walsh JH, Richardson CT, Frodtram JS. pH dependence of acid secretion and gastrin release in normal and in ulcer subjects. $\mathcal{F}$ Clin Invest 1975;55:462-8.

3 Levi S, Beardshall K, Haddad G, Playford R, Ghosh P, Calam J. Campylobacter pylori and duodenal ulcers: the gastrin link. Lancet 1989; i:1167-8.

Marshall BJ, Armstrong JA, McGechie DB, Glancy RJ. Attempt to fulfil Koch's postulates for pyloric Campylobacter. Med f Aust 1985;142:436-9. 